\title{
8
}
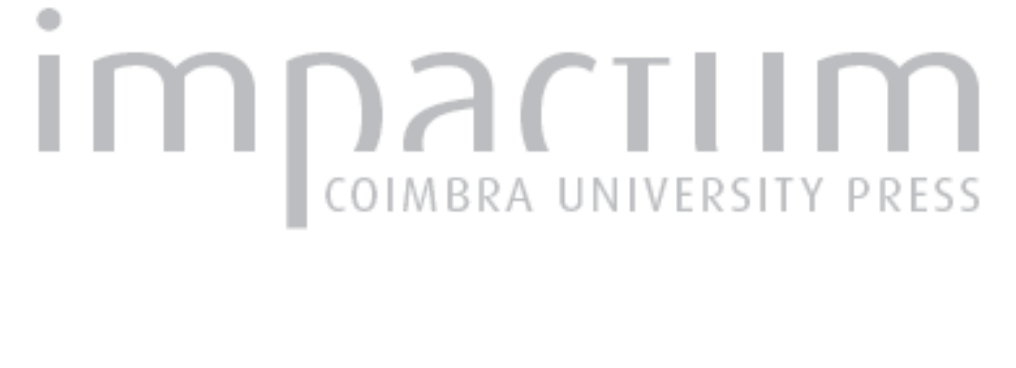

Contributo dos espaços verdes para o bem-estar das populações: estudo de caso em Vila Real
Autor(es):
Silva, Joana; Nogueira, Helena
Publicado por: Imprensa da Universidade de Coimbra
URL persistente:
URI:http://hdl.handle.net/10316.2/36890
DOI:
DOI:http://dx.doi.org/10.14195/0871-1623_33_10

Accessed :

26-Apr-2023 00:25:16

A navegação consulta e descarregamento dos títulos inseridos nas Bibliotecas Digitais UC Digitalis, UC Pombalina e UC Impactum, pressupõem a aceitação plena e sem reservas dos Termos e Condições de Uso destas Bibliotecas Digitais, disponíveis em https://digitalis.uc.pt/pt-pt/termos.

Conforme exposto nos referidos Termos e Condições de Uso, o descarregamento de títulos de acesso restrito requer uma licença válida de autorização devendo o utilizador aceder ao(s) documento(s) a partir de um endereço de IP da instituição detentora da supramencionada licença.

Ao utilizador é apenas permitido o descarregamento para uso pessoal, pelo que o emprego do(s) título(s) descarregado(s) para outro fim, designadamente comercial, carece de autorização do respetivo autor ou editor da obra.

Na medida em que todas as obras da UC Digitalis se encontram protegidas pelo Código do Direito de Autor e Direitos Conexos e demais legislação aplicável, toda a cópia, parcial ou total, deste documento, nos casos em que é legalmente admitida, deverá conter ou fazer-se acompanhar por este aviso. 


\section{Cadernos de Geografia}
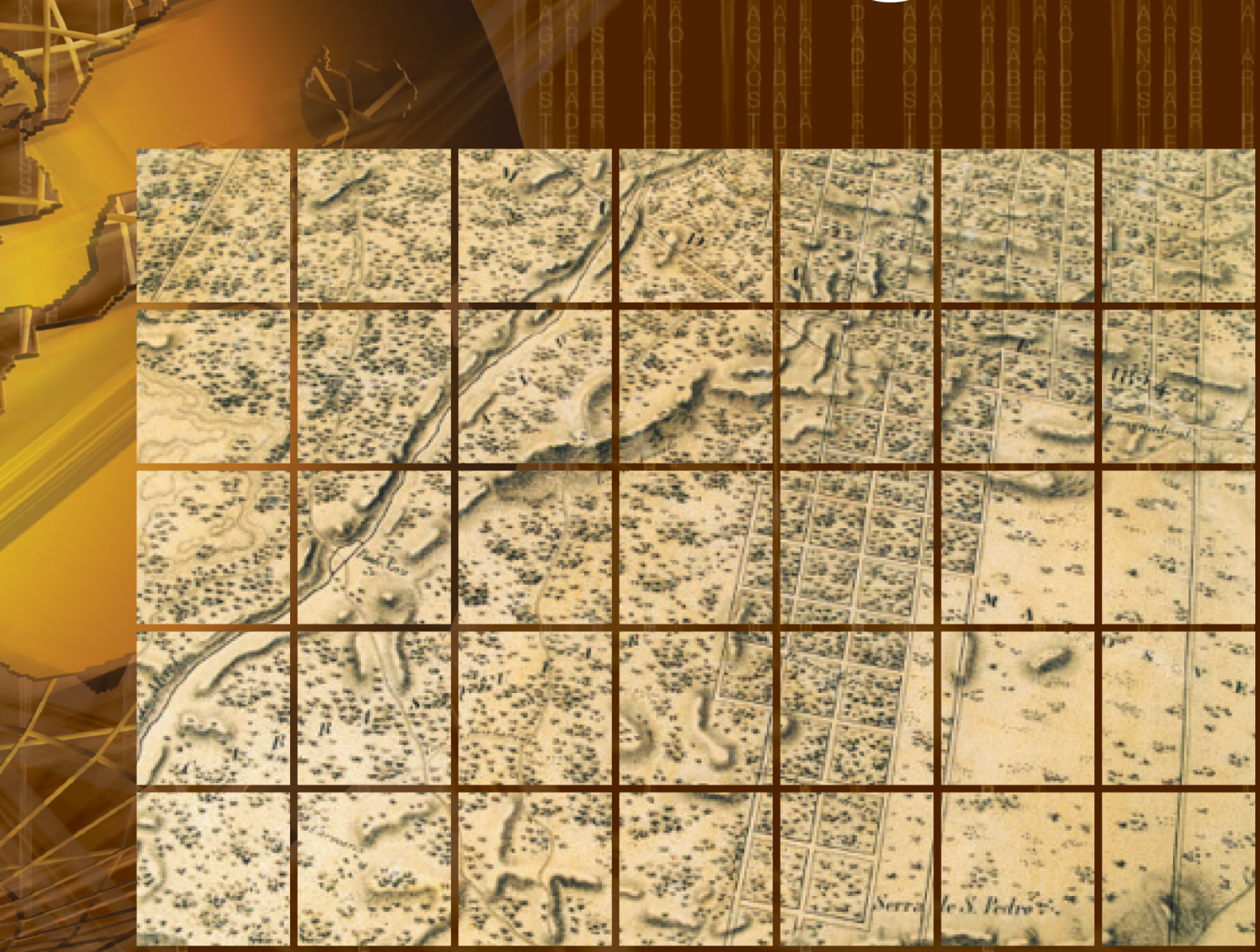

№ 33 - 2014

Imprensa da Universidade de Coimbra Faculdade de Letras | Universidade de Coimbra 


\section{Contributo dos espaços verdes para o bem-estar das populações - estudo de caso em Vila Real ${ }^{1}$ \\ Contribution of green spaces to the well-being of populations - a case study in Vila Real}

\section{Joana Silva}

Mestranda em Geografia Humana, Ordenamento do Território e Desenvolvimento. Faculdade de Letras. Universidade de Coimbra. juanasilva_103@hotmail.com

\section{Helena Nogueira}

Departamento de Geografia. Faculdade de Letras. Universidade de Coimbra. helenamarquesnogueira@hotmail.com

\section{Resumo:}

O conceito de saúde é atualmente entendido de uma forma positiva, acentuando a importância dos recursos sociais e pessoais, bem como das atividades físicas (CARTA DE OTTAWA, OMS, 1986). Considera-se também que a saúde pode ser promovida através de estratégias e ações não exclusiva, nem fundamentalmente, biomédicas, direcionadas a um conjunto alargado de determinantes sociais da saúde (CARTA DE OTTAWA, OMS, 1986). Os espaços verdes são hoje vistos como espaços promotores de recreio e lazer, propícios ao desenvolvimento de atividades diversas, como jogos, desporto, convívio e interação social, contribuindo para o prazer e bem-estar da população. 0 presente trabalho procura avaliar o contributo dos espaços verdes urbanos da cidade de Vila Real na melhoria da qualidade de vida da sua população. Avaliam-se os dois EVU mais importantes da cidade, o Parque do Corgo e o Parque Florestal.

Palavras-chave: Saúde. Bem-estar. Espaços verdes urbanos. Vila Real.

\section{Abstract:}

The concept of health is currently understood in a positive way, stressing the importance of social and personal resources, as well as physical activities (OTTAWA CHARTER, WHO, 1986). It is also considered that health can be promoted through strategies and actions not exclusively, nor primarily biomedical, targeted to a wide range of social determinants of health (OTTAWA CHARTER, WHO, 1986). Green spaces are now seen as leisure promoting, leading to the development of various activities such as games, sports and social interaction, thus contributing to the population well-being. This study evaluates the contribution of urban green spaces of Vila Real in improving the quality of life of its population. It assesses the two most important UGS of the city, the Corgo Park and Florestal Park.

Keywords: Health. Wellness. Urban green spaces. Vila Real.

\footnotetext{
1 Este trabalho corresponde à comunicação, com o mesmo título, apresentada no VIII Colóquio de Geografia de Coimbra, subordinado ao tema “Espaço, Natureza e Sociedade. A Geografia na Estratégia 2020 da Região Centro”, realizado na Faculdade de Letras da Universidade de Coimbra, nos dias 27 e 28 de março de 2014
} 


\section{Introdução}

Ao longo do tempo o conceito de saúde tem vindo a sofrer profundas alterações. A Organização Mundial de Saúde definiu-o como "estado de completo bem-estar físico, mental e social e não apenas a ausência de doença ou de enfermidade" (NogueIRA, 2008). Hoje, o conceito de saúde é menos utópico, mais operacional, definindo-se como uma capacidade funcional e adaptativa, um capital que permite ao indivíduo desempenhar as funções que the são solicitadas. É, ainda, uma construção sociocultural, podendo ser interpretada numa perspetiva individual, social e cultural. "A saúde deve estar repleta de estratégias e ações que contribuam para a melhoria do bem-estar das populações" (CARTA DE OTTAWA, OMS, 1986). Deve ser vista como um "recurso para a vida, assumindo-se como uma dimensão da qualidade de vida e não como um objetivo de vida" (Galinha e RibeIRo, 2005).

0 estado de saúde individual é resultante de fatores intrínsecos a cada indivíduo - imutáveis (como idade, género, genética) ou mutáveis (como comportamentos, estilos de vida, ocupação) e de fatores ambientais, correspondentes às características dos lugares em que se vive e trabalha. Assim, o espaço assume-se como uma variável fundamental nos resultados em saúde, e o geógrafo, enquanto especialista na interpretação do espaço, ganha uma nova relevância nas questões relacionadas com a saúde (Nogueira, 2008).

Um indivíduo saudável deve ser equilibrado corporal e mentalmente e bem ajustado ao seu meio físico e social, estando em controlo total dos seus recursos físicos e mentais (Almeida Filho et al, 1999). Percebe-se, então, que a saúde mental não é apenas a ausência de perturbações mentais, mas sim a capacidade de pensar coerentemente e de julgar; além da ausência de perturbações mentais, inclui dimensões positivas como o bem-estar, a perceção de auto eficácia, competência, potencial intelectual e emocional próprio (wHo, 2001), devendo ser perspetivada num contexto socioecológico. É neste contexto socioecológico, ou ambiental, de saúde que a geografia da saúde emerge como subdisciplina geográfica relevante, integrando e articulando saberes diversos, e preocupando-se com a necessidade de organizar o território de forma a promover a saúde da população. Planear espaços verdes urbanos (EVU) que minimizem e mitiguem os problemas ambientais existentes nas cidades, ao mesmo tempo que contribuem para a recuperação e promoção da saúde e bem-estar das populações é, pois, uma das temáticas da geografia da saúde.

O planeamento de EVU ganha relevância num mundo progressiva e massivamente urbanizado, onde se vive cada vez mais em ambientes construídos e artificializados. PARK (1973: 26) refere que "a cidade não pode ser vista meramente como um mecanismo físico e uma construção artificial. Esta é envolvida nos processos vitais das pessoas que a compõem; é um produto da natureza e particularmente da natureza humana" (LoBodA et al., 2005). É necessário criar nas cidades elementos que, acessíveis a toda a po- pulação, contribuam para a melhoria da sua saúde e bem-estar. Neste âmbito, deve fazer-se referência ao movimento das cidades saudáveis, entendidas como aquelas que "procuram proporcionar às suas populações mais saúde e melhor qualidade de vida, permitindo-lhes desenvolver as suas potencialidades" (NogueIRA, 2008: 71). A OMS define cidade saudável como aquela que coloca em prática, de modo contínuo, a melhoria do meio ambiente físico e social, utilizando todos os recursos da comunidade.

FADIGAS (1993) define os espaços verdes urbanos (EVU) como todos os jardins, parques urbanos, ou todas as áreas livres que estão ocupadas por vegetação em meio urbano (FonseCA et al, 2010). Estes espaços surgem com o objetivo de recriar a presença da natureza no meio urbano. São espaços que podem estar integrados no interior ou na zona periférica das cidades e que são muitas vezes considerados como "pulmões necessários à cidade" (LoBodA e DE ANGELIS, 2005). Uma das funções dos EVU é minimizar as tensões da vida citadina, amenizando os problemas sociais e ambientais urbanos, dado que apresentam vários benefícios para os lugares onde se localizam. Destes benefícios destacam-se os de nível ambiental, que correspondem à regularização da temperatura, renovação do ar, aumento da permeabilidade dos solos, aumento da biodiversidade, entre outros. Por outro lado, destacam-se os benefícios sociais e culturais, decorrentes da utilização destes espaços e correspondendo ao contacto com a natureza, manutenção do equilíbrio psicológico e físico, e melhoria da qualidade de vida, entre outros. Os EVU surgem assim como recursos e oportunidades do urbanismo saudável, dada a sua capacidade em atenuar os efeitos negativos do processo de urbanização e em promover a saúde da população.

Neste artigo são apresentados dois EVU da cidade de Vila Real, assim como alguns resultados referentes ao estudo desses dois parques. Os EVU em estudo representam os principais espaços verdes da cidade, com maior dimensão e características mais atrativas. Com o seu estudo, pretende-se ter um maior conhecimento destes espaços e perceber quão importantes são para a população que os frequenta, ao mesmo tempo que se pretende perceber se estes têm, ou não, alguma influência no bem-estar dos seus utilizadores.

\section{Dados e métodos}

Demograficamente, o concelho de Vila Real apresenta uma população residente de 51.850 indivíduos. Ocupando uma área total de $378,08 \mathrm{~km}^{2}$, a densidade populacional deste concelho é de aproximadamente $138 \mathrm{hab} / \mathrm{km}^{2}$. A cidade de Vila Real possui dois espaços verdes de maior dimensão e importância, o Parque do Corgo e o Parque Florestal. O Parque do Corgo, com cerca de $330.000 \mathrm{~m}^{2}$, está situado ao longo das margens do rio Corgo, e é considerado o verdadeiro pulmão da cidade. É um espaço amplo, que disponibiliza equipamentos como campos polidesportivos, itinerários pedestres, um parque infantil, e 
espaço para passeio e descanso. A sua formação está associada ao programa POLIS XXI. Quanto ao Parque Florestal nasceu nos anos 60 e tem cerca de 38.000 $\mathrm{m}^{2}$. É cercado a toda a volta por um muro e foi o EVU mais importante da cidade até à construção do Parque do Corgo. Atualmente pertence ao Instituto de Conservação da Natureza e das Florestas (ICNF).

Localizados na cidade de Vila Real, a escolha destes EVU justifica-se pela importância que representam no contexto urbano em que se inserem. Neste estudo, pretende-se conhecer as características dos dois EVU, ao mesmo tempo que se procura identificar as características que os tornam atrativos ou repulsivos.

Esta análise é feita com recurso a dois instrumentos de pesquisa, uma grelha de observação e um inquérito. Com a grelha de observação registaram-se informações relativas a diferentes características dos EVU: acessibilidade aos parques; atividades que se podem realizar; manutenção; segurança; oportunidades de lazer e redução de stress.

0 inquérito, realizado aos frequentadores dos EVU, possibilitou a recolha de informações relativas a dados pessoais (idade, género, estatuto socioeconómico); caracterização da utilização (frequência da visita ao parque; atividades realizadas); caracterização da saúde (bem-estar emocional e psicológico); impacte da visita ao parque no bem-estar mental dos utilizadores.

Para a análise foram utilizados 64 inquéritos, sendo 14 referentes ao Parque Florestal e 50 ao Parque do Corgo.

\section{Resultados}

Os resultados obtidos permitem concluir que o Parque do Corgo é um espaço mais atrativo do que o Parque Florestal. No entanto, os dois EVU são espaços de uso diário ou frequente, destinados principalmente ao passeio ou descanso dos frequentadores.

Com a análise das grelhas de observação, conclui-se que os dois parques estão bem localizados e apresentam boas condições de acessibilidade. Verifica-se que os EVU em estudo apresentam boas condições para a realização de várias atividades, tanto desportivas, como de passeio ou lazer. No que respeita à higiene e manutenção, o Parque Florestal apresenta condições muito deficientes; em oposição, o Parque do Corgo assume-se como uma referência, pelas boas condições de higiene e manutenção.

Em termos de segurança, e sendo esta vista como um dos parâmetros mais importantes para a frequência destes espaços, conclui-se pela vulnerabilidade do Parque Florestal, uma vez que os sinais de vandalismo são aí evidentes.

Por último, no que respeita ao Lazer e Redução de stress, conclui-se que estes espaços apresentam características bastante atrativas para desfrutar de momentos tranquilos, possibilitando o contacto com o espaço verde natural.

A análise dos inquéritos conclui que os utilizadores dos EVU são na sua maioria do sexo feminino
(62\% no Parque do Corgo e 57\% no Parque Florestal), revelando que as mulheres são as principais adeptas de espaços ao ar livre. Verifica-se ainda que estes são na sua maioria jovens, estudantes e em idade ativa, residentes em Vila Real, e cujas residências se encontram a uma distância ao parque entre os 5-10 minutos a pé, destacando-se assim o fator proximidade como determinante para a frequência destes espaços.

Quanto às atividades que são realizadas nos parques, os inquiridos revelam que a procura dos EVU se faz principalmente para lazer, destacando-se também a "redução de stress" e "descanso". É ainda de destacar a elevada percentagem da "prática de desporto” no Parque Florestal (Quadro I).

Quadro I

Atividades realizadas nos parques verdes

\begin{tabular}{|c|c|c|}
\hline Atividades & Parque Florestal & Parque Corgo \\
\hline Lazer & $34 \%$ & $46 \%$ \\
\hline Passeio animais & $3 \%$ & $7 \%$ \\
\hline Passeio crianças & $3 \%$ & $7 \%$ \\
\hline Desporto & $25 \%$ & $8 \%$ \\
\hline Ler/Estudar & $9 \%$ & $5 \%$ \\
\hline Descansar & $13 \%$ & $14 \%$ \\
\hline Redução stress & $13 \%$ & $12 \%$ \\
\hline Indicação médica & $0 \%$ & $1 \%$ \\
\hline
\end{tabular}

Relativamente à caraterização da saúde mental dos utilizadores, os resultados obtidos revelam que estes apresentam na sua maioria uma boa saúde, com apenas $14 \%$ dos inquiridos no Parque Florestal a reportarem doença mental ou emocional (depressão).

Os EVU em análise podem ser considerados como espaços promotores de uma vida mais saudável, dado que a sua frequência eleva o sentimento de bem-estar nos utilizadores, quer física quer psicologicamente. A comprovar esta afirmação encontram-se os resultados da pergunta relativa à perceção de bem-estar antes e após a visita aos parques, revelando que $26 \%$ dos utilizadores do Parque do Corgo e $43 \%$ dos utilizadores do Parque Florestal avaliavam o seu bem-estar no nível razoável antes da visita ao parque, passando a maioria destes a avaliá-lo no nível bom ou muito bom após a visita (Quadro II e III).

Quadro II

Perceção de bem-estar antes da visita aos parques

\begin{tabular}{|c|c|c|}
\hline Perceção & Parque Corgo & Parque Florestal \\
\hline Muito bem & $14 \%$ & $7 \%$ \\
\hline Bem & $60 \%$ & $43 \%$ \\
\hline Razoável & $26 \%$ & $43 \%$ \\
\hline Mal & $0 \%$ & $7 \%$ \\
\hline Muito mal & $0 \%$ & $0 \%$ \\
\hline
\end{tabular}

Quadro III

Perceção de bem-estar após a visita aos parques

\begin{tabular}{|c|c|c|}
\hline Perceção & Parque Corgo & Parque Florestal \\
\hline Muito bem & $58 \%$ & $29 \%$ \\
\hline Bem & $40 \%$ & $64 \%$ \\
\hline Razoável & $0 \%$ & $7 \%$ \\
\hline Mal & $2 \%$ & $0 \%$ \\
\hline Muito mal & $0 \%$ & $0 \%$ \\
\hline
\end{tabular}


Confirma-se assim tendência para a melhoria do bem-estar e qualidade de vida dos utilizadores com a frequência aos EVU; ao mesmo tempo, esta frequência diminui o stress e eleva a satisfação com a saúde pessoal.

$\mathrm{Na}$ classificação dos espaços verdes, os utilizadores classificam o Parque Florestal como "Razoável" e o Parque do Corgo como "Bom". Desta forma, 59\% dos utilizadores referem não encontrar "nenhum" problema no Parque do Corgo, enquanto o Parque Florestal apresenta "falta de limpeza”, “degradação" e "marginalidade" (Quadro IV).

Quadro IV

Problemas encontrados nos EVU

\begin{tabular}{|c|c|c|}
\hline Problemas & Parque Florestal & Parque Corgo \\
\hline Nenhum & $6 \%$ & $59 \%$ \\
\hline Dificuldade acesso & $6 \%$ & $6 \%$ \\
\hline Ruído urbano /Tráfego & $3 \%$ & $4 \%$ \\
\hline Adolescentes & $3 \%$ & $4 \%$ \\
\hline Grafitis & $3 \%$ & $4 \%$ \\
\hline Falta de limpeza & $34 \%$ & $7 \%$ \\
\hline Marginalidade & $7 \%$ & $9 \%$ \\
\hline Degradação & $29 \%$ & $7 \%$ \\
\hline
\end{tabular}

Os resultados obtidos revelam ainda que o Parque do Corgo é um espaço procurado por ser agradável, ter bom ambiente e ser um espaço calmo. Dadas as suas características, este espaço é considerado apropriado para fugir à rotina, relaxar e passear e estabelecer contactos sociais.

Por outro lado, o Parque Florestal é um espaço procurado por ser um espaço calmo e possuir características naturais atrativas. Todavia, este parque torna-se repulsivo pela falta de segurança, marginalidade e falta de conservação e manutenção.

\section{Conclusões}

As cidades organizam-se cada vez mais em conformidade e adequação às necessidades humanas, destacando-se a preocupação em criar ambientes saudáveis, que melhorem as condições de vida das populações. Os fundamentos do planeamento urbano saudável são a melhoria da qualidade do ambiente e a promoção da qualidade de vida e bem-estar das populações.

Em contextos massivamente urbanizados, os espaços verdes urbanos adquirem uma importância estratégica, uma vez que contribuem para a melhoria da qualidade ambiental, promoção de estilos de vida saudáveis e melhoria da qualidade de vida. Proporcionando aos seus frequentadores experiências restaurativas, contribuem especificamente para a melhoria do seu bem-estar mental, assumindo-se como recursos incontornáveis do planeamento urbano saudável.

Os resultados obtidos permitem concluir que o Parque do Corgo é um espaço mais atrativo do que o Parque Florestal, pelas oportunidades e condições de utilização que oferece. No entanto, os dois EVU são espaços de uso diário ou frequente, destinados principalmente a passeio ou descanso dos utilizadores. Apesar de serem procurados por toda a população, parece que a idade é um fator de exclusão, dado que na análise dos inquéritos a percentagem de utilizadores em idades mais avançadas revelou-se reduzida.

Os resultados mostram ainda que a permanência ou a frequência nestes espaços aumenta a perceção de bem-estar, mostrando que após a visita aos EVU os utilizadores sentem-se melhor do que quando chegaram ao local. Este resultado sugere que os EVU em análise possuem condições atrativas e restaurativas para a saúde física e mental, possibilitando a melhoria da saúde dos utilizadores.

Considerando a interação que existe entre lugar-saúde-lugar, e sabendo que lugares saudáveis geram comportamentos saudáveis, que por sua vez contribuem para a formação de lugares mais saudáveis, que potencialmente fomentarão comportamentos ainda mais saudáveis, é fundamental dotar as cidades de áreas verdes públicas, onde a população possa desfrutar de momentos de lazer e contacto com a natureza.

\section{Bibliografia:}

Alberto, K. e Lima, S. (2012) - “Áreas verdes e saúde: uma revisão das pesquisas experimentais". VI encontro nacional de ANPPAS, Brasil. Disponível em: http:// WWw. anppas.org.br/encontro6/anais/ARQUIVOS/GT4-574-309.pdf. Data de acesso: 15 de Fevereiro de 2014.

Almeida Filho, N.; Coelho, M. e Peres, M. (1999) - "O conceito de saúde mental". Revista USP, n43, pp. 100-125, São Paulo.

CARTA de OtTAWA (1986) - Primeira conferência internacional sobre promoção da saúde. Ottawa.

CARvalho, G. (2006) - Criação de ambientes favoráveis para a promoção de estilos de vida saudáveis. Universidade do Minho, Edições LIDEL.

FADIGAS, L. (1993) - A natureza na cidade, uma perspectiva para a sua integração no tecido urbano. Dissertação de Mestrado, Universidade Técnica de Lisboa, Lisboa.

FonseCA, F.; GonÇAlves, A. e Rodrigues, O. (2010) - “Comportamentos e perceções sobre os espaços verdes da cidade de Bragança”. Revista Finisterra, n²8, pp. 119-139, Bragança.

Galinha, I. e PAIS RIBEIRo, J. (2005) - “História e evolução do conceito de bem-estar subjectivo". Revista Psicologia, Saúde e Doenças, $\mathrm{n}^{\circ}$ 6, Faculdade de Psicologia e de Ciências da Educação, Universidade do Porto, Porto, pp. 203-214.

GonÇALVES, A. (2012) - “A utilização dos espaços verdes. Estudo de caso em três cidades espanholas". VII Colóquio de 
Geografia de Coimbra - Territórios contemporâneos em contexto de mudança, Cadernos de Geografia $\mathrm{n}^{\circ}$ 30/31. Coimbra, pp. 193-202.

GouveIA, N. (1999) - "Saúde e meio ambiente nas cidades: os desafios da saúde ambiental”. Revista Saúde e Sociedade, n 8, São Paulo, pp. 49-61. Disponível em: http://www. scielo.br/pdf/sausoc/v8n1/05.pdf.

Guite, H.; Clark, C. e Ackrill, G. (2006) - "The impact of the physical and urban environment on mental well-being", Elsevier, $\mathrm{n}^{\circ} 120$, pp. 1117-1126, Disponível em: http:// www.nchh.org/portals/0/contents/article0806.pdf.

Loboda, C. e De angelis, B. (2005) - “Áreas verdes públicas urbanas: conceitos, usos e funções”, Revista Ambiência, $\mathrm{n}^{\circ}$ 1, volume 1, Brasil, pp. 125-139.

LoPERA, F. (2005) - "Las zonas verdes como factor da calidad de vida en las ciudades". Revista Ciudade y Territorio, Estudios Territoriales, $\mathrm{n}^{\circ} 144$, Valencia.

MARques, T. (1999) - "Um território em mudança: padrões territoriais, tipologia urbana e dinâmicas". Inforgeo, $n^{\circ} 14$, Lisboa, pp. 21-42.

NoguelRA, H. (2007-2008) - "Saúde (d)nos lugares - a problemática dos territórios promotores de saúde". "Cadernos de geografia”, n²6/27, Coimbra, pp. 85-99

Nogueira, H. (2008) - Os lugares e a Saúde. Imprensa da Universidade de Coimbra, Coimbra.
PARK, R. E. (1973) - "A cidade: sugestão para a investigação do comportamento humano no meio urbano". In: 0 fenômeno urbano, $2^{\text {a }}$ ed., Zahar Editores, Rio de Janeiro, pp. 26-57.

Perehouskei, N. e Angelis, B. (2012) - "Áreas verdes e saúde: paradigmas e experiências". Diálogos e Saberes, $\mathrm{n}^{\circ}$ 1, v. 8, Brasil, pp. 55-77. Disponível em: http://seer. fafiman.br/index.php/dialogosesaberes/article/ viewFile/173/100.

SANTANA, P. (2000) - "Contribuição da geografia da saúde para o conhecimento das desigualdades em saúde e bem-estar no mundo". Cadernos de geografia, $\mathrm{n}^{\circ} 19$, Coimbra, pp. 43-67.

Santana, P. (2007) - A cidade e a saúde. Edições Almedina, Coimbra.

Vries, S.; Verheis, R.; Groenewegen, P. e Spreeuwenberg, P. (2003) - "Natural environments - healthy environments? An exploratory analysis of the relationship between greenspace and health". Environment and planning, Vol. 35, pp. 1717-1731. Disponível em: http://nvl002. nivel.nl/postprint/pppp1696.pdf.

World health organization (2001) - Relatório Mundial de saúde. Saúde mental: nova concepção, nova esperança. Direção-Geral da Saúde, OMS. 